\title{
An experimental and numerical investigation of the effect of macro-textured tool surfaces in hot stamping
}

\author{
Kailun Zheng ${ }^{1}$ • Denis J. Politis ${ }^{1} \cdot$ Jianguo Lin $^{1} \cdot$ Trevor A. Dean ${ }^{2}$
}

Received: 3 August 2015 / Accepted: 2 November 2015 / Published online: 20 November 2015

(C) The Author(s) 2015. This article is published with open access at Springerlink.com

\begin{abstract}
This paper presents a method of increasing drawability of materials in hot stamping processes using forming tools with macro-scale textures on the tool surfaces. Firstly, a series of tool texture designs and orientations were presented and a test programme was designed for the experimental investigation. Top-hat shape drawing experiments in cold and hot stamping conditions were conducted to evaluate the effect of macro-scale tool surface textures on the material drawing. Texture directional and texture feature effects of the blankholders on the draw-ability of the material have been investigated. A finite element model of the top-hat drawing process with textured tool surfaces has been established and validated from experimental data. Further FE process modelling has been carried out and the effects of texture features and forming speed have been studied. The relationships between texture designs and material drawing results have been analysed. The developed FE model can provide a guide to design the geometry of tool textures and optimise the hot stamping process parameters.
\end{abstract}

Keywords Hot stamping · Tool surface texture - Texture ratio $\cdot$ Flange ratio $\cdot$ Top-hat drawing

Denis J. Politis

denis.politis06@imperial.ac.uk

1 Department of Mechanical Engineering, Imperial College London, Exhibition Road, London SW7 2AZ, UK

2 School of Mechanical Engineering, University of Birmingham, Edgbaston, Birmingham B15 2TT, UK

\section{Introduction}

The use of formed aluminium alloy sheet components has grown in popularity in both automotive and aircraft industries in recent years due to its light weight and low cost $[1,2]$. In order to manufacture complex-shaped sheet components, hot stamping is used to improve the poor ductility of aluminium alloys at room temperature. Lin et al. [3] developed a novel hot stamping process for aluminium alloy sheets, which is known as "Solution Heat treatment, cold die Forming and Quenching" (HFQ $\left.{ }^{\mathrm{TM}}\right)$. In this process, a work-piece is heated to its Solution Heat Treatment (SHT) temperature to dissolve the precipitates within the primary $\alpha$-Al matrix [4] and simultaneously stamped and quenched within cold dies. For heattreatable aluminium alloys, the formed components can be artificially aged to maximum strength [5].

The thermal and tribology properties at the tool/work-piece interface significantly affect the draw-ability and formability for hot stamping processes [6-9]. Although these properties have been extensively investigated for the hot stamping of high strength steels, there has been limited research into the effect of these properties for hot stamping of aluminium alloys [10] and in particular for forming with HFQ conditions. With regard to reducing the friction coefficient at the tool/workpiece interface, the use of lubricants can enhance the ability to produce a good quality component [11]. To increase the effect of a lubricant treatment, a variety of surface engineering methods, such as diamond-like coatings (DLC) [12-14] and micro-scale texturing, have been applied to tool surfaces [15, 16]. The DLCs act as solid lubricants and simultaneously increase wear resistance and reduce friction [12]. Wank et al. [17] investigated the capacity of DLC coatings in lubricant free cold massive forming of AA6016, the results showed that the capacity of DLCs depended strongly on tool surface roughness. Heinrichs et al. [18, 19] also demonstrated the cold 
forming of aluminium alloys including AA6082, where less material transfer between the tool and aluminium alloy workpiece occurs when a more advantageous topography is used with polishing the interfaces.

Texturing is another feasible approach to enhance the lubrication effect [20]. Costa and Hutchings [21, 22] found friction was greatly reduced when a tool surface was patterned with grooves perpendicular to the drawing direction in strip drawing processes. These grooves were believed to act as lubricant reservoirs to enhance the lubrication effect. Similar studies have also been conducted by Qiu et al. [23] to investigate the texture patterns on friction coefficient. Kovalchenko et al. studied the frictional and wear behaviour of textured tool surfaces in the lubricated condition, using laser surface texturing, where friction coefficient is reduced in conformal and relatively low-pressure lubricated contacts [24]. Research has also been conducted on the friction coefficient using textured forming dies in metal forming process $[25,26]$. In addition, to evaluate the thermal effect of textured tool surfaces, Xie et al. performed experiments using multi-scale-structured surfaces and spray cooling, where a $65 \%$ heat transfer enhancement was determined [27]. Moreover, tool surface textures have been used to obtain a tailored strength distribution on the formed part, as patented by Gestamp Hardtech for press hardening operations [28].

However, these extensive studies on the surface texturing were mainly focused on the texture dimensions at micro-scale. In practical stamping processes, the tool dimensions are normally at meter scales and macro tool surface texture could affect the frictional property and heat transfer significantly, and thus the flow and draw-in of materials in hot stamping. Compared with micro-scale surface textures, little research has been carried out on macro-scale surface textures for stamping. Franzen et al. [29] investigated friction coefficient at the tool/work-piece interfaces using selective texturing on the tool surfaces as shown in Fig. 1, a significant increase in friction coefficient was found due to the material elastic deformation near the texture area and local plastic deformation on the sheet surface. Kleiner et al. [30] investigated the friction behaviour of sheet metal in strip drawing tests using tools with different milled surfaces. The textures were oriented along and across the material flow direction and in different zigzag directions. The friction coefficient was clearly increased in the zigzag direction, while linear textures, parallel to the drawing direction, do not increase compared to non-textured, grinded tool surfaces.

In this paper, the effects of macro-scale surface textures on the HFQ stamping process of aluminium alloys are described. Top-hat part drawing experiments were conducted, in which a channel section with flanges (top hat section) was drawn. The effects of various macro-scale tool textures on draw-ability were compared for cold and hot alloy sheet to identify the detailed effects of the textured tool surfaces. A flange ratio was defined to compare effects of texture orientation and texture ratio on material draw-ability. Part shapes formed using tools with different surface texture designs were compared. FE simulations were carried out using the commercial FE code Pamstamp. Using this thermal-mechanical coupled FE simulation, the effect of a non-uniform temperature field could be captured. FE simulation results were validated using experimental data of flange ratios and normalised thickness distribution in shapes with different forming parameters. The validated FE model was then applied to investigate more detailed aspects of material flow in the drawing processes.

\section{Experimental set-up and test programme}

\section{Material and test-piece}

Commercial AA6082-T6 condition aluminium sheets with a thickness $1.5 \mathrm{~mm}$ were used as test-pieces. The chemical composition is provided by the materials supplier [31] and given in Table 1 . The typical solution heat treatment temperature for the alloy is $525^{\circ} \mathrm{C}[32]$.

Rectangular test-pieces with dimensions: $240 \mathrm{~mm}$ length and widths of 86,90 , and $94 \mathrm{~mm}$ were produced by laser cutting. For the cold stamping tests, test-pieces were tested in the annealed condition by heating the as received $\mathrm{T} 6$ material to $415^{\circ} \mathrm{C}$ and soaking for $1 \mathrm{~h}$ and subsequently furnace cooling [33]. Hot stamping test samples used were the received T6 condition and tested under HFQ conditions by first solution heat treating at $525^{\circ} \mathrm{C}$ for $2 \mathrm{~min}$.

\section{Experimental set-up and tool preparation}

In order to perform the top-hat drawing tests, a tool was mounted onto a $1 \mathrm{MN}$ ESH hydraulic press with a maximum

Fig. 1 Selective surface texturing on the tool surfaces in parallel, perpendicular and zigzag orientation corresponding to the material flow direction [29]
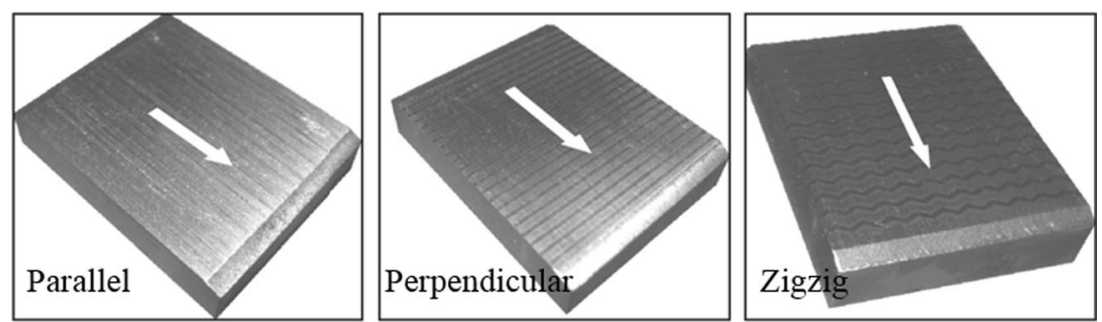
Table 1 Chemical composition of AA6082 [31]

\begin{tabular}{llllllllll}
\hline Element & $\mathrm{Mn}$ & $\mathrm{Fe}$ & $\mathrm{Mg}$ & $\mathrm{Si}$ & $\mathrm{Cu}$ & $\mathrm{Zn}$ & $\mathrm{Ti}$ & $\mathrm{Cr}$ & $\mathrm{Al}$ \\
\hline$\%$ & $0.4-1.0$ & $0-0.5$ & $0.6-1.2$ & $0.7-1.3$ & $0-0.1$ & $0-0.2$ & $0-0.1$ & $0-0.25$ & Balance
\end{tabular}

forming speed of $600 \mathrm{~mm} / \mathrm{s}$ and a total stroke of $100 \mathrm{~mm}$. The tool used for the tests is shown in Fig. 2a. As can be seen, the top-hat shaped die is attached to the ram whereas the rectangular punch is fixed to the base of the tool. Rectangular blankholders $(120 \times 100 \mathrm{~mm})$ for locating the test-piece material are positioned on either side (both left and right) of the punch and are secured to the middle plate of the tool. The blankholders can be replaced with blankholders of varying textures in order to test macro-texture effects on drawing. Moreover, located above the blankholder and secured to the die are inserts located on both the left and right hand side of the die. As with the blankholders, these are replaceable and allow different textures and surface treatments to be applied without the need to machine multiple dies. The material used for the punch and die was H13 tool steel whereas G3500 cast iron [34] was used for the blankholders and inserts.

Fig. 2 The stamping test rig design and set-up details
During testing, the test-piece is positioned onto the blankholders. The ram subsequently moves downwards closing the gap between the die and blankholders. Once the die is in contact with the blankholders, the assembly moves down over the stationary punch which subsequently draws the material into the die. During the entire forming process, the blankholding force can be adjusted through the use of blankholding force bars attached to a gas cushion positioned beneath the tool. By altering the pressure of the gas spring system located beneath the test rig, the blankholding force and in-die quenching force can be varied. In this system shown in Fig. $2 b$ and c, there are a total of 28 gas springs, with a maximum extrusion load of $50 \mathrm{kN}$. This gas spring system can be divided into two groups. The first group consists of four gas springs connected to the blankholding force bars in order to support the middle plate and supply

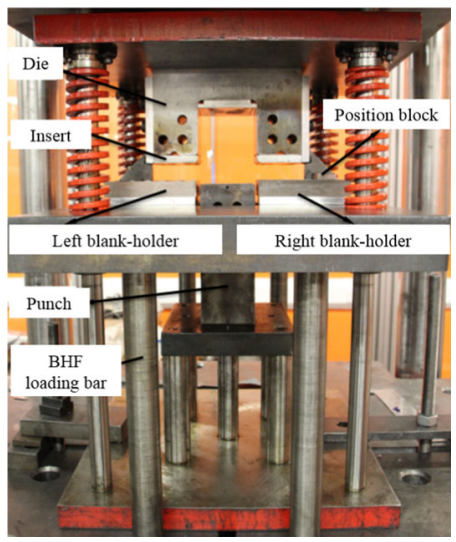

(a) Stamping rig set-up

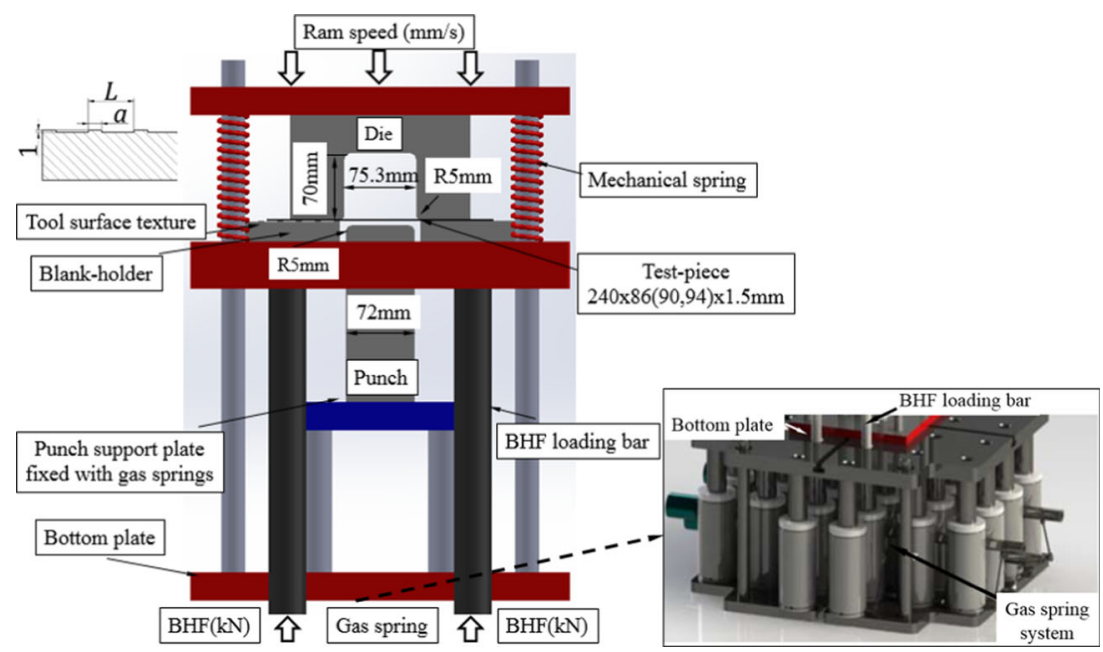

(b) Schematic design of the stamping rig

(c) Gas spring system 
the blank-holding force (Fig. 2b). The second group consists of the remaining 24 gas springs which support the bottom plate of the test rig, and provide the in-die quenching force for the formed component.

The effect of macro-scale textures on the draw of material were tested by applying textures of depth $1 \mathrm{~mm}$ onto the blankholders as shown in Fig. 3a. A texture ratio $a / L$ was defined, where $a$ is the width of the texture and $L$ is the distance between the beginning of one texture to the beginning of the subsequent texture. In this case, a value of $a / L=1.0$ indicates no texture i.e., full contact between the test-piece and the blankholder surface whereas $a / L=0$ indicates a knife-edge contact to the test-piece. For the purpose of work conducted in this paper, texture ratios of $0.3,0.5$ and 1.0 were used which were machined onto the blankholders through the milling process as in Fig. 3b. In order to assess the effect of texture direction, the above texture ratios were machined onto the blankholder in both the parallel and perpendicular direction to the material draw.

\section{Test procedure}

For the performance of cold stamping tests, the test-piece material was first annealed according to the process presented in "Material and test-piece". Moreover, a range of texture ratios and texture orientations of $a / L=0.3,0.5$ and 1.0 in both the parallel and perpendicular direction were tested. The tests were performed by maintaining the texture ratio of the rightside blankholder as $a / L=1.0$ whilst varying the textures on the left-side blankholder. By positioning different blankholders on each side, the amount of material drawn from each

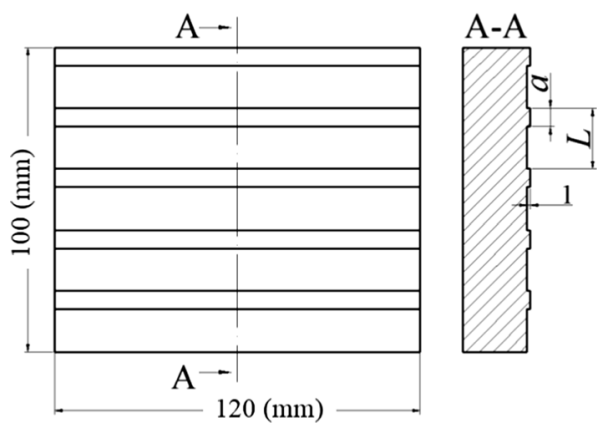

(a) Tool surface texture definitions

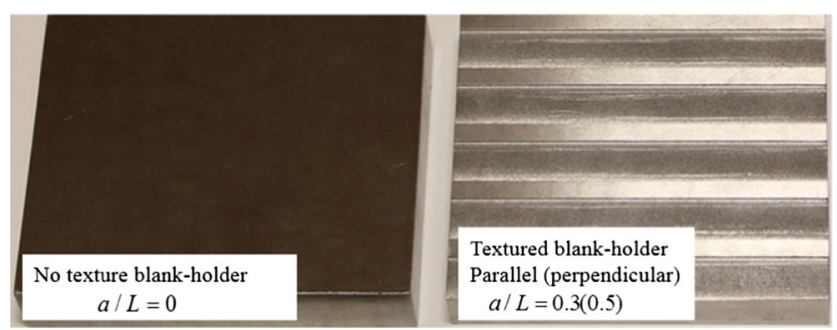

(b) Manufactured tool surface textures

Fig. 3 Textured tool surfaces and texture definitions blankholder will vary, which allows the effect of the textures to be assessed. Moreover, in order to assist material flow, Omega 35 lubricant was applied evenly on both blankholders, punch and die insert surfaces.

For hot stamping tests, the test-pieces were solution heat treated at $525^{\circ} \mathrm{C}$ for $2 \mathrm{~min}$ and quickly transferred to the tools and formed within $7 \mathrm{~s}$ resulting in a maximum temperature loss of no greater than $55^{\circ} \mathrm{C}$, in order to maintain the temperature above the precipitate formation temperature [35]. Finally, the formed top-hat shape was quenched within the cold dies to room temperature. The blankholder ratios and orientation used for the tests were the same as those of cold stamping. In addition to varying texture design, hot stamping tests involved the variation of blank-holding force at 5,10 and $15 \mathrm{kN}$. The ram speed was fixed at $150 \mathrm{~mm} / \mathrm{s}$.

\section{Experimental results}

\section{Effect of texture orientation}

As stated above, varying the texture of the left blankholder whilst maintaining a constant texture on the right blankholder will affect the material draw on each blankholder. This can be quantified by assessing the length of the flange region material. In order to reflect the flange difference on the two sides, a flange ratio $\zeta$ can be defined as a ratio of the lengths of the two flange regions as shown in Eq. (1).

$\zeta=L_{\text {left }} / L_{\text {right }}$

Where $L_{\text {left }}$ is the flange length of the formed part corresponding to the left-hand side blank-holder, $L_{\text {right }}$ is the flange length of the formed part corresponding to the right-hand side. The flange length is defined as the distance between the flange edge and the edge of the radius on the formed part. As there may be variation of flange length through the depth of the part, the flange lengths are calculated as the average value between the front and the back to minimise the geometry error as shown in Fig. 4a.

Figure 4 presents cold stamped parts with tool textures: (a) no surface texture $a / L=1.0$, (b) perpendicular texture $a / L=0.3$ and (c) parallel texture $a / L=0.3$ on the left-hand side blankholder, while the right-hand side blank-holder was fixed with no texture $(a / L=1.0)$. The flange ratio $\zeta$ in Fig. $4 \mathrm{~b}$ increased to 1.35, compared with 1.03 shown in Fig. 4a, which indicated that the material on the left-hand side of (b) was constrained from being drawn into the die, hence resulting in a longer flange length on the left blankholder. Examination of the underside view of the flange regions (Fig. 4a) shows a smooth surface finish whereas the region of Fig. $4 \mathrm{~b}$ involving the perpendicular blankholder shows an obvious ploughing effect. This is due to the texture edge applying a constraining 
Fig. 4 Texture orientation effect on the draw-ability and part quality with a blank-holding force $10 \mathrm{kN}$ for cold stamping processes

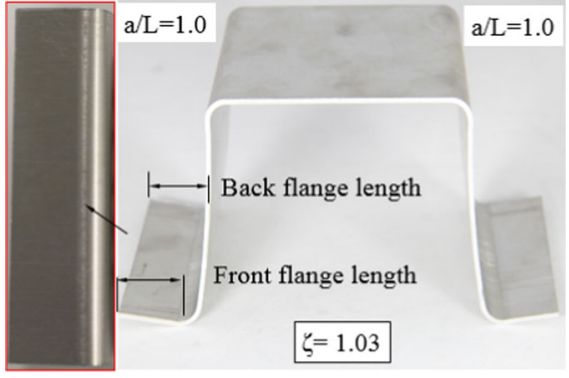

(a) Left: $\mathrm{a} / \mathrm{L}=1.0 ;$ Right: $\mathrm{a} / \mathrm{L}=1.0$

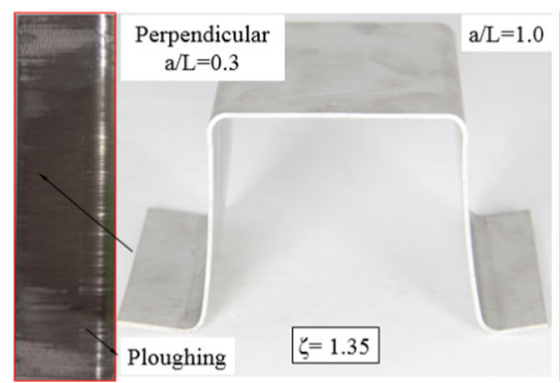

(b) Left: Perpendicular: $\mathrm{a} / \mathrm{L}=0.3$; Right: $\mathrm{a} / \mathrm{L}=1.0$

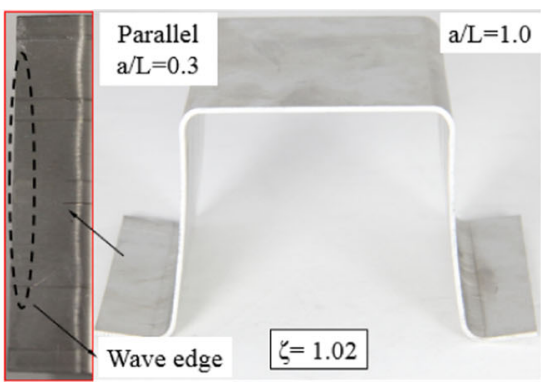

(c) Left: Parallel: $\mathrm{a} / \mathrm{L}=0.3$; Right: $\mathrm{a} / \mathrm{L}=1.0$ effect on the deformed material as illustrated in Fig. 5 and caused scratches on the flange area as shown in Fig. 4b. As shown in Fig. 5, when a blank-holding force is applied on the blank using a perpendicular texture orientation, the blank material is deformed elastically and a relative thickness variation will occur with the texture edge constraining material draw and causing the ploughing phenomena.

Figure $4 \mathrm{c}$ shows the formed part using a parallel texture $a /$ $L=0.3$, where the flange ratio $\zeta$ was 1.02 , which is not a significant change compared with Fig. 4a. This indicates that that the ploughing effect is not obvious when the texture orientation is aligned in the parallel direction to material flow. Material deformation could still be observed on the underside view of the contact surface. Another typical characteristic of the parallel texture is the wave profile at the outer edge of the flange resulting from friction force distribution. Material in contact with the blank-holder was constrained by friction whereas material located above the groove of tool texture was free to flow.

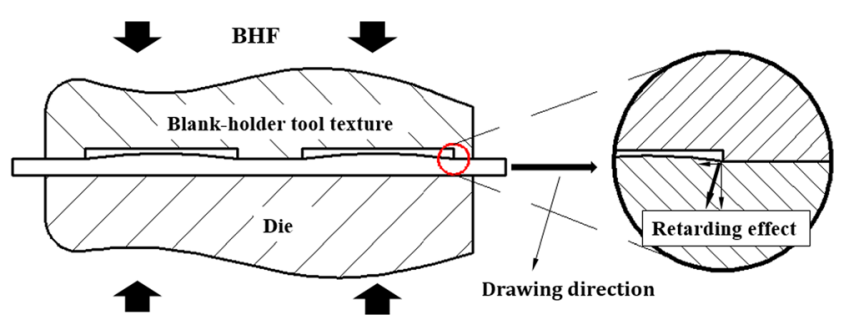

Fig. 5 Illustration of the ploughing effect on the material drawing using the perpendicular tool texture

\section{Effect of tool texture feature}

With regard to the constraining effect of perpendicular tool texture on the material draw, cold and hot stamping using parallel tool textures with different texture ratios were conducted. Parallel tool texture blankholders (Left: $a / L=0.3$ and Right: $a / L=1.0$ ) were used with blank-holding forces of $30 \mathrm{kN}$ when performing cold formed components and $15 \mathrm{kN}$ for hot formed components. For the cold formed part shown in Fig. $6 a$, the flange ratio $\zeta$ was 1.17 , a $13.6 \%$ increase from that in Fig. 4a, which might illustrate that, the parallel tool texture had a constraint effect at large blank-holding force, but not as severe as the perpendicular texture.

Figure $6 \mathrm{~b}$ shows the hot formed part using the same tool texture design with Fig. 6a. The flange length on the left-hand side (parallel $a / L=0.3$ ) was much shorter than the right-hand side $(a / L=1.0)$. The flange ratio $\zeta$ was significantly decreased to 0.49 , which illustrates that surface texture has a significant effect on improving the draw-ability in hot stamping. Regarding the non-uniform temperature field of the test-piece, temperature of the punch nose region was higher than that of flange area. As the material strength is higher at lower temperatures, the strength of straight side wall and flange area material is higher than the punch nose area material. Due to this, deformation may concentrate on the high temperature region which might cause failure to occur once necking occurred at a higher blank-holding force. Using a blank-holder with surface texture on the left-hand side, the contact area becomes much smaller compared with the full contact case of the right-hand blankholder. Hence, the flange area 
Fig. 6 Effect of tool texture design on the draw-ability in the stamping processes. The tool texture designs are: Left: Parallel $\mathrm{a} / \mathrm{L}=0.3$; Right: $\mathrm{a} / \mathrm{L}=1.0$ with blank-holding forces a $30 \mathrm{kN}$ and b $15 \mathrm{kN}$

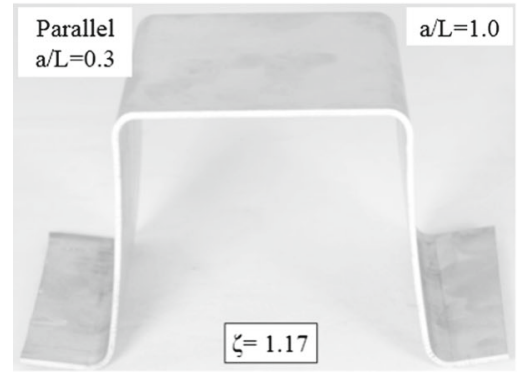

(a) Cold formed part

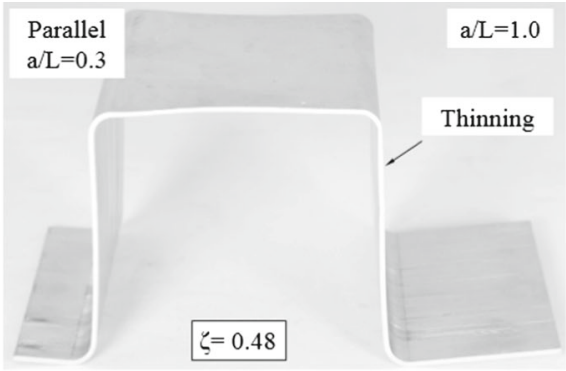

(b) Hot formed part temperature of the left flange would be much higher, and closer to the punch nose temperature when compared to the large temperature difference between the punch nose area and the flange area on the right side using the non-texture blankholder. Therefore, the lower temperature difference on the lefthand side might contribute to a more uniform material deformation and avoid the concentrated material deformation at the punch nose area. Further analysis will be given according to FE simulation results presented in the following sections.

\section{Numerical modelling}

\section{Material model for AA6082}

As hot stamping involves deformation of material at elevated temperature, both temperature and strain rate dominate alloy visco-plastic deformation characteristics [36]. In this paper, a set of dislocation-based hardening constitutive equations developed by Lin and Liu [37] are used to model the viscoplastic flow of AA6082 under the HFQ forming conditions, where the damage parameter for AA6082 was determined by Mohamed et al. [4] and used in this work. The full set of the constitutive equations are listed as Eq. (2) to Eq. (6) below.

$\dot{\varepsilon}_{p}=\left(\frac{\sigma /\left(1-f_{d}\right)-R-k}{K}\right)^{n_{1}}$

$\dot{R}=0.5 B \bar{\rho}^{-0.5} \dot{\bar{\rho}}$

$\dot{\bar{\rho}}=A(1-\bar{\rho})\left|\dot{\varepsilon}_{p}\right|-C \bar{\rho}^{n_{2}}$

$\dot{f}_{d}=D 1 f_{d}^{d_{1}} \cdot \dot{\varepsilon}_{p}^{d_{2}}+D 2 \dot{\varepsilon}_{p}^{d_{3}} \cosh \left(D_{3} \varepsilon_{p}\right)$

$\sigma=E\left(1-f_{d}\right)\left(\varepsilon_{T}-\varepsilon_{P}\right)$

Equation (2) describes the visco-plastic material flow using a power law, where $\dot{\varepsilon}_{p}$ is the plastic strain rate and $n_{1}$ is the strain rate-hardening exponent [37]. $R$ is the isotropic hardening variable, $k$ is the initial yield stress of the material, and $f_{d}$ is the area fraction of damaged material. Equation (3) describes the material hardening based on the accumulation of dislocation density, $\dot{R}$ is the isotropic hardening rate, which is related to the normalised dislocation density $\bar{\rho}$ in the material, $\bar{\rho}=\left(\rho-\rho_{0}\right) /\left(\rho_{\max }-\rho_{0}\right)$, where $\rho_{0}$ is the material initial dislocation density, $\bar{\rho}$ varies from 0 (initial state) to 1 (dislocation network saturated state) [32], and calculated by Eq. (4). Equation (5) represents the damage parameter and models diffusion and plasticity induced cavity expansion [4], $\dot{f}_{d}=r_{d}^{2} / l^{2}$, where $r_{d}$ is an effective cavity size that includes the radial extent of diffusion zone, and $l$ is the cavity spacing. The damage parameter increases from the initial state prior to deformation $f_{d}=0$, up to a critical value taken as 0.7 in this study [4]. Equation (6) is based on Hooke's law, where $\sigma$ is the flow stress, $E$ is the Young's modulus of the material, $\varepsilon_{T}$ and $\varepsilon_{P}$ are the total and plastic strain respectively.

The parameters $K, k, B, C E, D_{1}, D_{2}$ are temperaturedependent material parameters. $A, n_{1}$ and $n_{2}$ are temperatureindependent material constants. $D_{3}, d_{1}, d_{2}$ and $d_{3}$ are material constants. The temperature-dependent parameters can be calculated as Arrhenius equations and are presented in Eq. (7)-(13), with $R_{g}$ being the universal gas constant.

$K=K_{0} \exp \left(\frac{Q_{K}}{R_{g} T}\right)$

$k=k_{0} \exp \left(\frac{Q_{k}}{R_{g} T}\right)$

$B=B_{0} \exp \left(\frac{Q_{B}}{R_{g} T}\right)$

$C=C_{0} \exp \left(\frac{-Q_{C}}{R_{g} T}\right)$

$D_{1}=D_{10} \exp \left(\frac{Q_{D_{1}}}{R_{g} T}\right)$

$D_{2}=D_{20} \exp \left(\frac{Q_{D_{2}}}{R_{g} T}\right)$ 
$E=E_{0} \exp \left(\frac{Q_{E}}{R_{g} T}\right)$

The constants for these equations determined by [4] are shown in Table 2.

\section{FE model and simulation process}

FE simulations were performed using a range of parallel tool textures to evaluate effects of texture ratios on the material drawing. The simulations were performed using the commercial finite element software Pamstamp under 3D conditions to provide a better understanding of the part temperature field and material deformation during the forming processes. The simulation of the forming process, including the pre-deformed blank shape, the blankholder textures, punch, as well as the post formed top-hat shape, dimensions, loading and boundary conditions are shown in Fig. 7.

For the tools and test-piece material, shell elements (Belytschoko-Tsay) were used, with the tools being treated as rigid bodies. The number of test-piece elements is 20640 which is sufficiently large to guarantee the simulation accuracy, while those of the tools are 2160, 3040 and 576 for punch, die and blankholder (full contact case) respectively to improve the simulation efficiency. The process parameters used for the simulations are presented in Table 3.

To model the HFQ process, the initial test-piece (AA6082) temperature before forming was set to $470{ }^{\circ} \mathrm{C}$, due to the temperature loss that occurs during transfer of the test-piece from the furnace to the tool as determined experimentally in "Test procedure". The initial temperature of the punch, die and blank-holder tooling components was set to a room temperature of $20^{\circ} \mathrm{C}$. The element type selected for the blank was Belytschoko-Tsay with one integration point at the mid-plane in order to reduce simulation time without significant loss to numerical accuracy of the model as the temperature variation across the thickness of the sheet material is small owing to the thickness dimensions being an order of magnitude smaller than the width and depth dimensions. For tool shell elements, the thermal thickness was defined as $6 \mathrm{~mm}$.

The thermal conductivity of AA6082 blank was defined as $170 \mathrm{~mW} / \mathrm{mm} . \mathrm{K}$ [38] and the thermal conductivities of tool steel and cast iron were defined as 20 and $40 \mathrm{~mW} / \mathrm{mm} . \mathrm{K}$ for cast iron respectively [39]. Moreover, the specific heat of the blank, tool steel and cast iron were defined as 8.9E-9, 6.5E-8 and $4.6 \mathrm{E}-8 \mathrm{~mJ} /$ tonne.K respectively [39]. For heat transfer analysis, Newton's cooling law was applied to investigate the heat transfer between the tool and test-piece. As the interface heat transfer coefficient is a function of gap and pressure [40], the interface heat transfer coefficient between aluminium alloy and tool material was determined from the literature [38, 41], as shown in Tables 4 and 5 and implemented into the FE code by a look-up window. The large forming speed and short forming time allowed for the effects of convection and radiation between the test-piece and air to be neglected.

Other material properties such as density, Young's modulus and Poisson ratio were applied as: 2.7 E-9 tonne $/ \mathrm{mm}^{3}$, $70 \mathrm{GPa}, 0.33$ for aluminium and $7.8 \mathrm{E}-9$ tonne $/ \mathrm{mm}^{3}$, $210 \mathrm{GPa}, 0.3$ for tool steel, and $7.5 \mathrm{E}-9$ tonne $/ \mathrm{mm}^{3}$, $130 \mathrm{GPa}, 0.3$ for cast iron material [36, 39]. The friction coefficients in the simulation were selected as, $\mu=0.09$ for cold forming and $\mu=0.1$ for hot forming as was determined by the friction coefficient tests using lubricant Omega-35 by Foster et al. [38].

In the FE simulation, the HFQ process was divided into three stages: blank positioning, clamping, and forming. In the blank positioning stage, the encastre boundary condition was applied on the die, to restrict all degrees of freedom. The test-piece was positioned onto the die, using an implicit convergence test to calculate the end of this stage. In the blank positioning stage, the encastre boundary condition was still applied on the die, with the blank-holders having all degrees of freedom restricted except in the vertical direction ( $\mathrm{z}$ direction). The end of the clamping stage was defined when the gap between the blank-holder and die equals the work-piece thickness. The subsequent forming stage was applied to deform the test-piece into the die cavity shape. As HFQ process is a high speed forming process, an explicit calculation method was applied for this stage. During this stage, the encastre boundary condition was used for the die and blank-holders, with the punch being allowed to move in the vertical direction. The end of the forming stage was controlled by the pinch test between the punch and die. In-die quenching, which is the

Table 2 Material constants of the visco-plastic constitutive equations for AA6082 [4]

\begin{tabular}{lllllll}
\hline$B_{0}(\mathrm{MPa})$ & $k_{0}(\mathrm{MPa})$ & $K_{0}(\mathrm{MPa})$ & $Q_{E}(\mathrm{~J} / \mathrm{mol})$ & $Q_{C}(\mathrm{~J} / \mathrm{mol})$ & $Q_{B}(\mathrm{~J} / \mathrm{mol})$ & $Q_{k}(\mathrm{~J} / \mathrm{mol})$ \\
4.91 & 0.89 & 0.219 & 12,986 & 3393.4 & 6679 & $n_{2}$ \\
$Q_{K}(\mathrm{~J} / \mathrm{mol})$ & $Q_{D_{1}}(\mathrm{~J} / \mathrm{mol})$ & $Q_{D_{2}}(\mathrm{~J} / \mathrm{mol})$ & $E_{0}(\mathrm{MPa})$ & $n_{1}$ & $d_{1}$ \\
27.687 & 6408.4 & 119,804 & 322.81 & 5 & 1.8 & 1.2 \\
$d_{2}$ & $d_{3}$ & $D_{10}$ & $D_{20}$ & $D_{3}$ & $C_{0}$ & $A$ \\
1.0101 & 0.5 & 10.32 & $5.49 \mathrm{E}-19$ & 26.8 & 0.26 & 13 \\
\hline
\end{tabular}


Fig. 7 FE model and simulation mesh

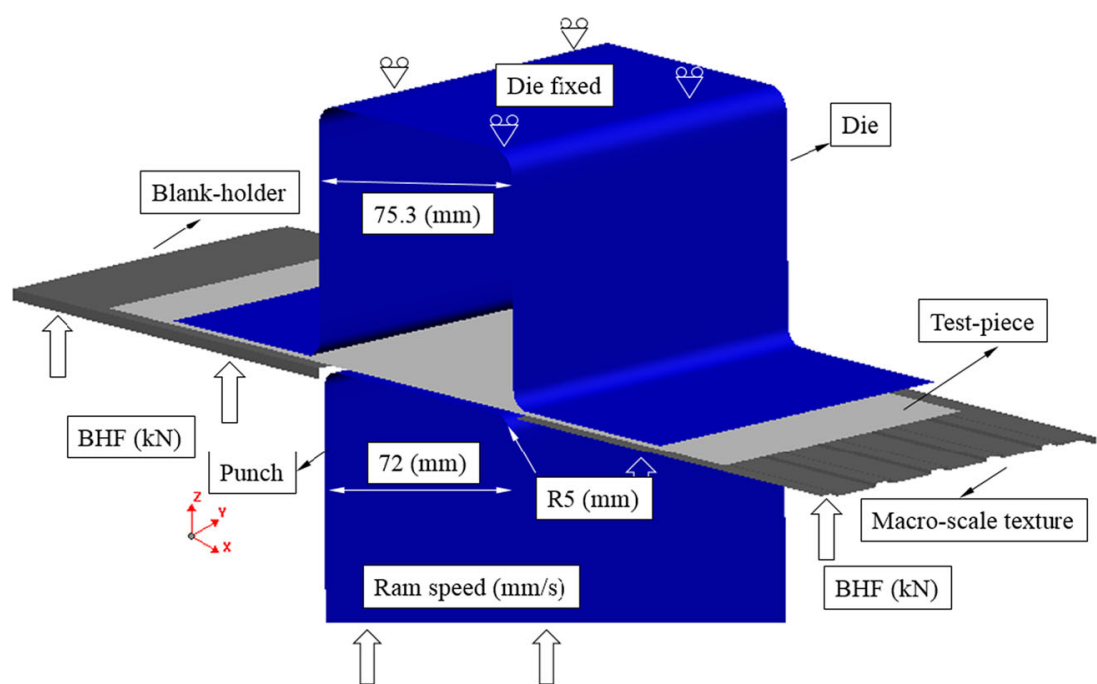

terminal stage of the process that improves material microstructure and strength was ignored in the simulations as this stage does not affect material draw and the evaluation of post-formed component strength is not subject to the current study.

\section{Computational results}

\section{FE model verification}

In order to validate the FE model, experimental and computational results of normalised thickness variations in Eq. (14) and flange ratios in Eq. (1) were compared for different tool designs in cold and hot stamping conditions. The experimental and simulation normalised thickness distributions $\left(t / t_{0}\right)$ were compared by taking a cross-section $10 \mathrm{~mm}$ from the component from the beginning of the left flange to the end of the right flange, defined as the section S-S in Fig. 8a, taking the edge of left side as the origin point and measuring in $5 \mathrm{~mm}$ intervals along the cross-section curve by digital Vernier callipers. In addition, flange ratios $\zeta$ predicted by the simulation were compared with measured flange lengths of the formed components using digital callipers. In order to minimise

Table 3 Process parameters in FE simulation

\begin{tabular}{lll}
\hline Process parameters & Cold stamping & Hot stamping \\
\hline Texture orientation & Parallel & Parallel \\
Texture ratio & $0.1-1.0$ & $0.1-1.0$ \\
Temperature $\left({ }^{\circ} \mathrm{C}\right)$ & Test-piece: 20 Tool: 20 & Test-piece: 470 Tool: 20 \\
$\begin{array}{l}\text { Forming speed } \\
(\mathrm{mm} / \mathrm{s})\end{array}$ & 150 & $150,300,600$ \\
$\mathrm{BHF}(\mathrm{kN})$ & $10,20,30,40$ & $5,10,15$ \\
\hline
\end{tabular}

geometry error, the front flange length and back flange length were both measured according to the definition in Fig. 4 "Effect of texture orientation".

$\hat{t}=t / t_{0}$

Where $t$ is the part thickness, $t_{0}$ the initial thickness and $\hat{t}$ the normalised thickness.

Figure 8a shows the simulation of a hot stamped part displaying the major strain distribution. The tool texture designs used are: Left: parallel $a / L=0.3$ and 0.5 Right: $a / L=1.0$, with a blank-holding force $15 \mathrm{kN}$ at a forming speed $150 \mathrm{~mm} /$ $\mathrm{s}$. The flange length difference could be captured by FE simulation. By comparing to an experimentally formed component under these conditions, the difference in flange ratio was 10.4 and $1.5 \%$, for texture ratios $a / L=0.3$ and 0.5 respectively. Further flange ratio validations under different forming conditions are shown in Fig. 10 in "Effect of texture feature".

Figure $8 \mathrm{~b}$ shows the normalised thickness variations of the cold and hot stamped parts at different positions along section S-S, using different tool designs: Left: parallel $a / L=0.3$ and 0.5 , Right: $a / L=1.0$. The symbols indicate the measured experimental normalised thickness and the solid lines indicate the computational normalised thickness. The maximum differences between experimental data and simulation data were, for texture ratio $a / L=0.3$ and $a / L=0.5,2$ and $1 \%$ in the cold stamping condition and 4.9 and $4.6 \%$ in the hot stamping condition. The larger variation in the hot

Table 4 Interface heat transfer coefficient as a function of gap [38]

\begin{tabular}{llll}
\hline Gap width (mm) & 1.05 & 0.6 & 0.0 \\
Heat transfer coefficient $\left(\mathrm{mJ} / \mathrm{mm}^{2}\right.$.s.K) & 0.04 & 0.07 & 0.8 \\
\hline
\end{tabular}


Table 5 Interface heat transfer coefficient as a function of pressure [41]

$\begin{array}{lllllll}\text { Pressure }(\mathrm{GPa}) & 0 & 0.01 & 0.02 & 0.03 & 0.04 & 0.05\end{array}$

$\begin{array}{lllllll}\text { Heat transfer coefficient } & 0.4 & 17.748 & 20.303 & 20.512 & 20.531 & 20.531\end{array}$ $\left(\mathrm{mJ} / \mathrm{mm}^{2} . \mathrm{s} . \mathrm{K}\right)$

stamping results may be due to the test-piece temperature loss during transfer from the furnace to the tool being greater than the estimated amount, as well as variations in the friction coefficient value defined in the FE simulation.

By comparing the normalised thickness between the experimental and simulation results for both cold and hot stamping, good agreements have been demonstrated for the macrotextures and texture ratios used. Hence, it is assumed that the FE model developed in this paper can be used to predict and investigate the material flow in the top-hat shape drawing processes using macro-textures.
Fig. 8 Comparisons of experimental (symbols) and computation (solid curves) normalised thickness variations in both cold and hot stamped parts using different tool designs. Blank-holding force $20 \mathrm{kN}$ for cold stamping and $15 \mathrm{kN}$ for hot stamping at a forming speed $150 \mathrm{~mm} / \mathrm{s}$

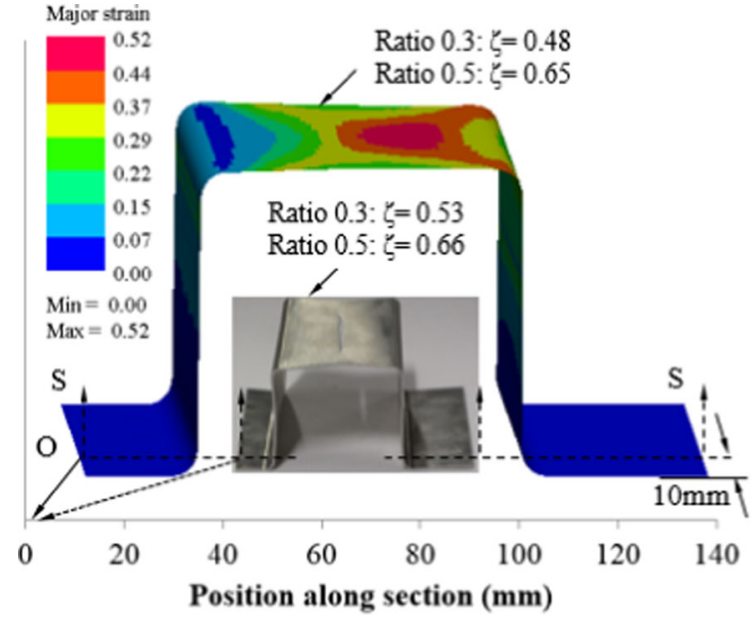

(a) Flange ratio $\zeta$ variation and section profile
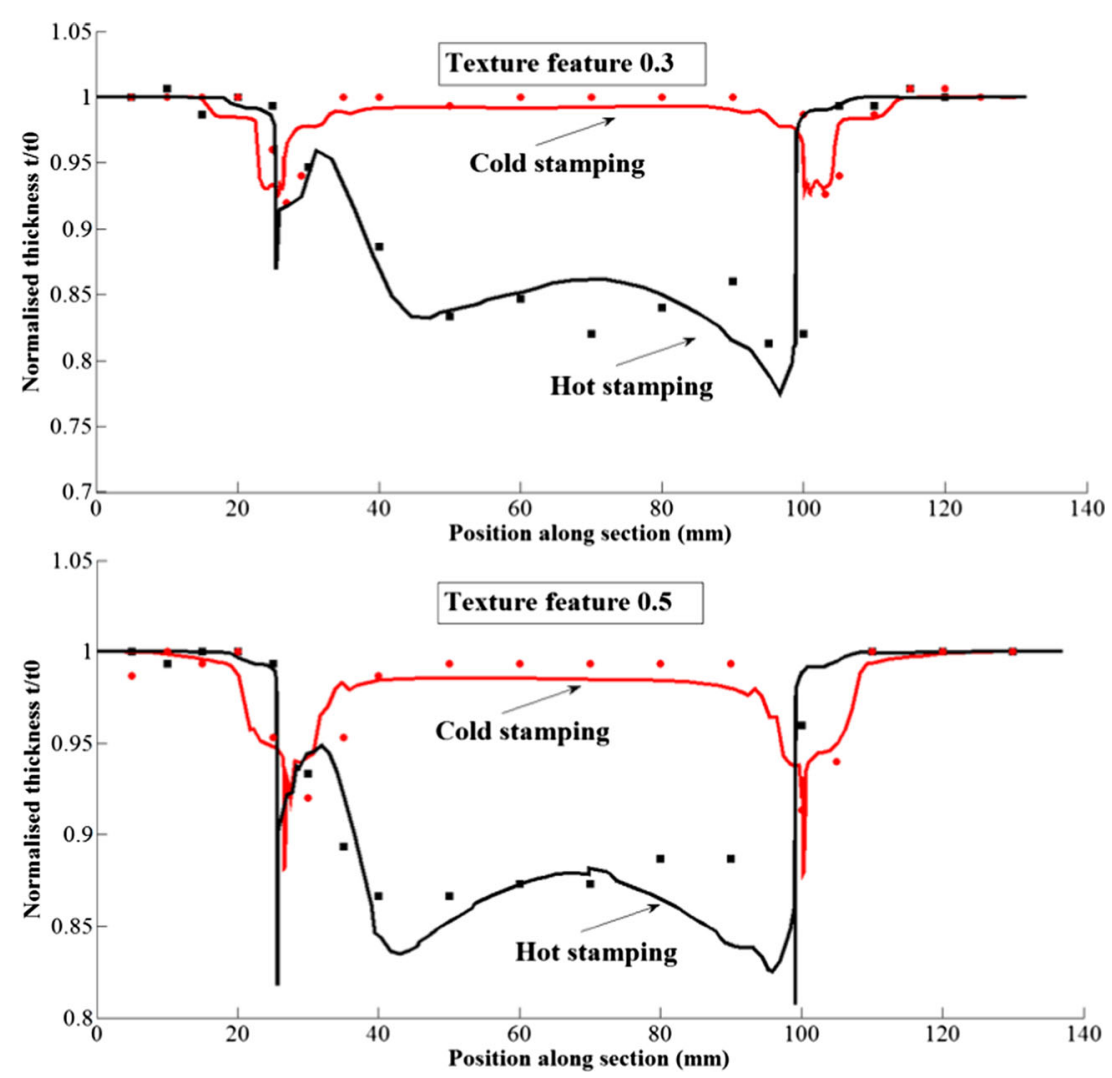

(b) Normalised thickness variations for texture ratio 0.3 and 0.5 


\section{Effect of temperature}

Figure 9 shows the temperature distributions and evolution in the hot formed part using macro-texture blank-holders (Left: parallel $a / L=0.3$, Right: $a / L=1.0$ ) with a blank-holding force $15 \mathrm{kN}$ at a forming speed $150 \mathrm{~mm} / \mathrm{s}$. The test-piece temperature reduces due to heat transfer to the forming tools during forming. Significant heat transfer phenomena could be
Fig. 9 Temperature contours and evolutions of section L-L (solid lines) and section R-R (dash lines) for the tool surface design (Left: parallel a/L $=0.3 ;$ Right: $\mathrm{a} / \mathrm{L}=1.0)$ at different time stages

\begin{tabular}{|c|}
\hline Nodal temperature \\
\hline 465.97 \\
414.23 \\
362.49 \\
310.74 \\
259.00 \\
207.26 \\
155.52 \\
103.77 \\
\hline
\end{tabular}

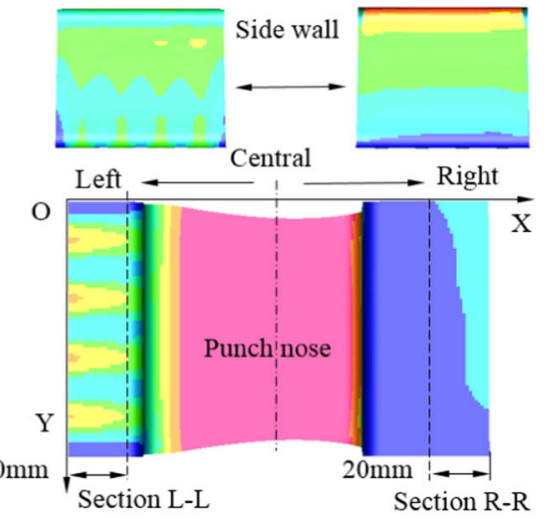

(a) Temperature contour of the hot stamped part using parallel macro-textured left blankholder

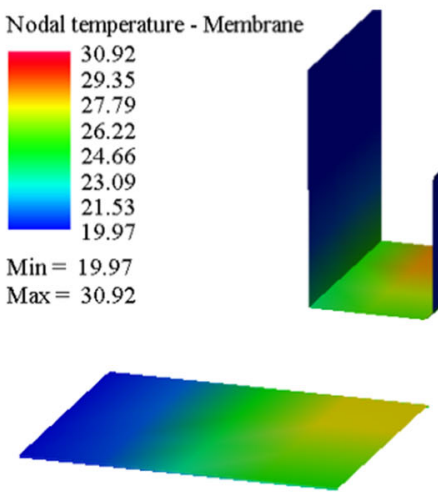

No texture blank-holder
Die
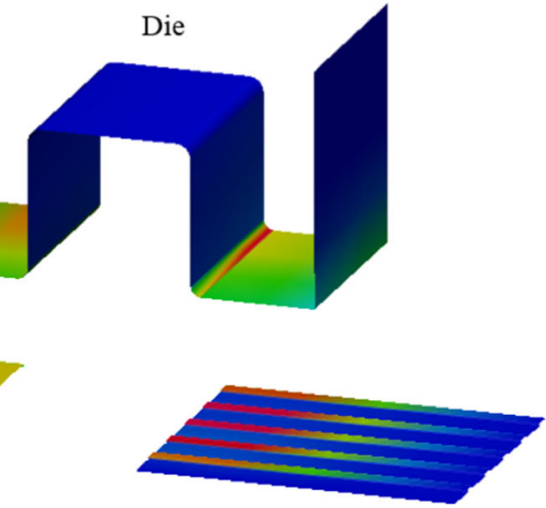

Textured blank-holder (b) Temperature contours of the hot stamped tools using parallel macro-textured left blankholder

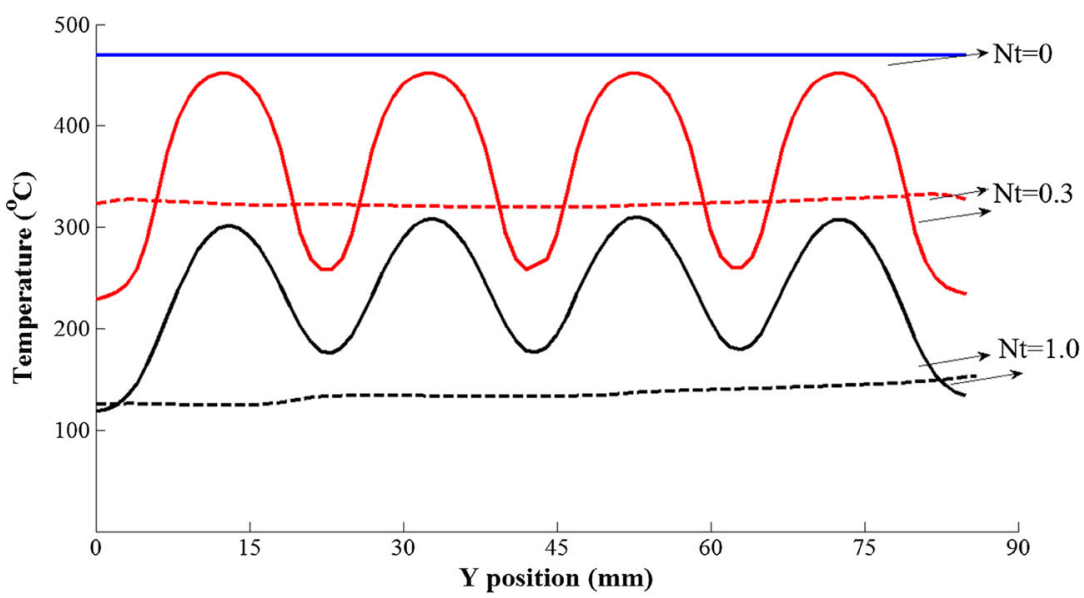

(c) Temperature evolution of the hot formed part 
observed between hot sheet blank and tools as shown in Fig. 9a and b. Hence the use of a macro-textured blank-holder generates a non-uniform temperature field at the flange zones of the test-piece in Fig. 9a. Unless significant thickness deformation occurs, the test-piece contacts the peaks of macrotexture on the blank-holders but not the grooves. Due to this, the temperature of the metal in these zones is believed to decrease quicker than the material without tool contact because of the heat conduction between the tool and test-piece. From the temperature distribution contour in Fig. 9a, on the right-hand side of this top-hat part, the punch nose area temperature was highest and the flange area was the lowest. This large temperature distribution may cause non-uniform deformation when a large blank-holding force is applied. The reason for this is that the material at the punch nose area has the highest temperature, as during deformation there is conduction on only the punch side, and therefore the material has the lowest strength. As the flange area material strength is higher, it therefore becomes easier to have localised deformation on the punch nose area rather than to draw the flange material into the die once necking occurs in this nose area. However, compared with the full contact case between the die and blankholder on the right-hand side, the use of macro-scale surface textures on the left-hand side maintains an elevated temperature for test-piece material at the flange area and side wall area as shown in Fig. 9a. As the temperature difference between the left flange and punch nose is smaller than when compared to the right flange and punch nose, it becomes easier to draw the left flange material into the die, because the strength of material at the punch nose area and side wall area material are relatively higher.

In addition, in the depth (y) direction of the flange area shown in Fig. 9a, the temperature varies at discrete distances. The temperature evolution of the left flange and right flange areas was selected by taking sections L-L and R-R at a distance of $10 \mathrm{~mm}$ from the outer flange edge. In order to quantitatively reflect temperature evolution during forming, a time stage factor $N_{t}$ is defined, which is equal to the time from start to an instant time point during forming divided by the whole forming time, $N_{t}=0$ indicates the initial stage of the forming process, and $N_{t}=1.0$ indicates the final stage of the forming process. A value of $N_{t}=0.3$ is an intermediate stage of forming.

Figure 9c shows the temperature evolution at different time stages. The solid line indicates section L-L while the dash line indicates section R-R. When $N_{t}=1.0$, the minimal temperature drops from the initial temperature 470 to $302.2^{\circ} \mathrm{C}(35.7 \%)$ on the left-hand side and $124.6{ }^{\circ} \mathrm{C}(73.5 \%)$ on the right-hand side. In addition, considering the non-uniform temperature field on the left side of the test-piece due to the tool texture (Fig. 9b), nodal temperature without tool texture contact is higher than that with contact. Therefore, it can be concluded that macro-textures have a significant effect on reducing the temperature loss during forming, thus maintaining the test-piece at a higher temperature.

\section{Effect of texture feature}

Figure 10 shows the texture feature effect on material drawability. The defined flange ratio $\zeta$ in Eq. (1) is used to reflect the material drawing condition on the two sides with different texture ratios. In order to minimise the number of tests, the righthand side surface was fixed with a texture ratio $\mathrm{a} / \mathrm{L}=1.0$, while the left-hand side blank-holders had different texture ratios $\mathrm{a} / \mathrm{L}=0.1$ to 1.0 with a 0.1 increment in the FE simulation. The comparison of experimental flange ratios with computational results in Fig. 10 could further validate the FE model.

Figure 10a shows that the flange ratio $\zeta$ increases with the increase of the texture ratio on the left side for the same blankholding force. This may be due to two reasons: firstly, the contact area was smaller using a small texture ratio, and the test-piece temperature at the flange area was maintained higher, and the temperature difference between the punch nose area and flange area was smaller compared with non-textured side as discussed above. At a sufficiently high blank-holding force, once necking occurred, this large temperature difference could enlarge the non-uniform deformation on the non-textured side and cause the flange length to differ. In addition, a small texture ratio results in a small area being compressed between the blankholders and hence there is less material subject to friction during draw, which could help material flow into the die and decrease the flange difference between the two sides. It was found that the lowest flange ratio $\zeta$ is 0.48 with a blankholding force $15 \mathrm{kN}$ in the simulation.

Using the same texture ratio on the left side blank-holder, the flange ratio increases with decreasing blank-holding force. Using high blank-holding force provides a high contact pressure, where the temperature of the work-piece drops at a greater rate than a low blank-holding force case. The temperature difference between the two blank-holders is enlarged, which results in a larger flange length difference, and hence a decreasing flange ratio $\zeta$. Taking texture ratio 0.5 as an example, the experimental flange ratio $\zeta$ could be decreased from 0.91 to 0.66 (27.5\%), for blank-holding forces 5 and $15 \mathrm{kN}$ respectively.

Comparing the experimental data (symbols) and the computational results (solid lines) in Fig. 10a, the maximum difference is $26 \%$, occurring at a texture ratio 0.3 . This difference is significantly less, at $9.2 \%$ for the texture ratio 0.5 and $2.4 \%$ for the texture ratio 1.0 . Using a small texture ratio, the actual contact area between the tool and test-piece was small. The increased deviation for smaller texture ratios could be the result of machining tolerances of the small textured surface, as a deviation on a small texture ratio will have a greater effect compared to a large texture ratio. Furthermore, another cause of deviation could be due to the thermal expansion of the test-piece at elevated temperatures which may cause unequal initial flange lengths on each side of the work-piece. Such thermal expansion phenomena were not included in simulation work. 
Fig. 10 Effect of texture ratio on the flange ratios of the hot stamped parts with tool texture designs (Left: parallel $a / L=0.1-$ 1.0; Right: $a / L=1.0$ ) with a different blank-holding forces and b different forming speeds. The solid curves are computational results and the symbols are experimental results

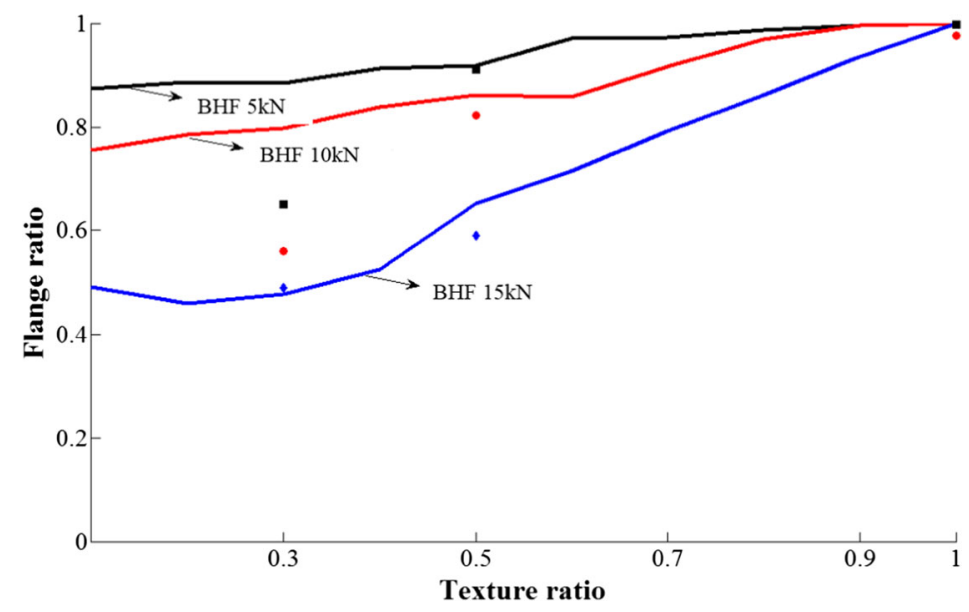

(a) Effect of texture ratio on the flange ratios of the hot stamped parts with blank-holding forces 5, 10 and $15 \mathrm{kN}$ at a forming speed $150 \mathrm{~mm} / \mathrm{s}$.

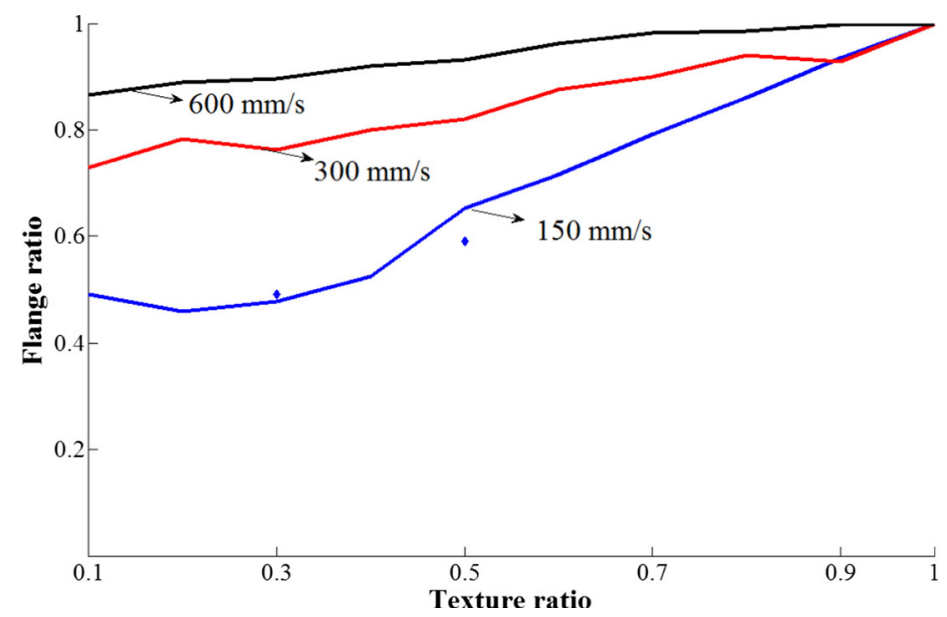

(b) Effect of texture ratio on the flange ratios of the hot stamped parts with a blank-holding force $15 \mathrm{kN}$ at forming speeds 150,300 and $600 \mathrm{~mm} / \mathrm{s}$.
Figure 10b shows the effect of material flow with textured blankholders compared to forming speed. The flange ratio $\zeta$ increases with increasing texture ratio at a given forming speed, similar to the trend shown in Fig. 10a. Another feature which can be seen is that for a given texture ratio, an increase in forming speed reduces the overall forming time, which results in a lower temperature loss on both blankholders. Therefore, for a low forming time, the work-piece temperature difference on either blankholder will exhibit less variation and hence result in a more uniform deformation and a larger flange ratio $\zeta$.

\section{Effect of forming speed}

Figure 11 shows the effect of forming speed on the normalised thickness distribution of hot stamped parts for a given tool texture design: Left: parallel $a / L=0.3$, Right: $a / L=1.0$. Three forming speeds, 75,150 and $600 \mathrm{~mm} / \mathrm{s}$, were chosen to investigate the effect of forming speed on the draw-ability in hot stamping using macro-texture tools. A section is located on the centre-line of the part, taking the outside edge of the left side flange as the origin. The normalised thickness distributions for forming speeds 150 and $75 \mathrm{~mm} / \mathrm{s}$ have a similar

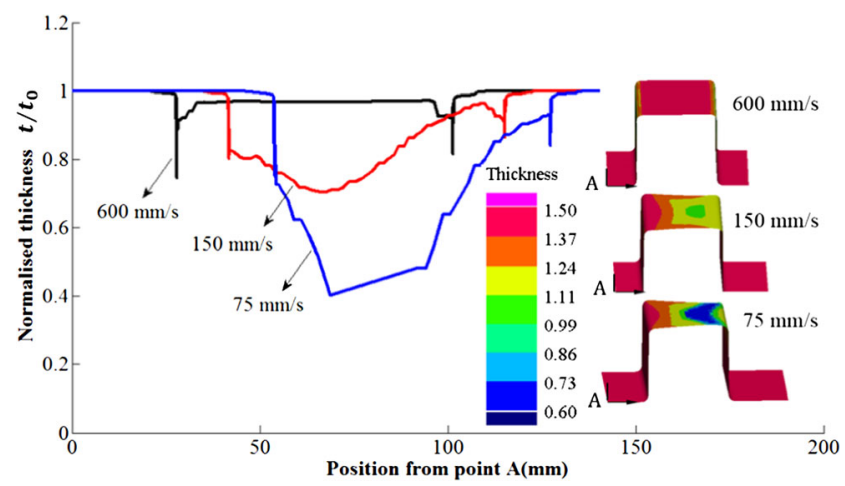

Fig. 11 Effect of forming speed on normalised thickness variation in the hot stamping processes with the tool surface texture design (Left: parallel: $a / L=0.3$; Right: $a / L=1.0$ ) with a blank-holding force $15 \mathrm{kN}$ 
trend, the maximum thinning is located at the top surface (punch nose section), shifting to the right side for this blankholder combination. Normalised thickness increased with increasing forming speed, which means less thinning occurs at a higher forming speed. This can be explained by the influence of forming speed on material hardening, where the hardening effect is greater at high forming speeds due to the strain rate effects on forming the visco-plastic alloy [36]. In addition, a higher forming speed reduced the contact time between the tool and test-piece and thus heat loss was reduced, resulting in a temperature that was higher and more uniform and hence leading to higher ductility and more uniform flow. As shown in Fig. 11, at a forming speed of $600 \mathrm{~mm} / \mathrm{s}$, the hot stamped part had no obvious necking, unlike the parts formed at 75 and $150 \mathrm{~mm} / \mathrm{s}$. High speed thus enhances the isothermal nature of the process [36].

\section{Conclusions}

The work described in this paper has investigated the effect of rectilinear macro-textures on metal flow in the cold and hot stamping of a top-hat shape; a channel with flanges. Perpendicular tool textures corresponding to the material flow direction had constraint effect on material flow as the material deformation due to the large blank-holding force, the flange ratio was increased to 1.35 , compared with 1.03 using nontexture on the two sides in cold stamping process.

In hot stamping processes, a texture parallel to metal flow can significantly improve draw-ability. Good agreement exists between FE computed and experimental flange ratios and normalised thickness distributions. The minimal flange ratio was 0.46 for $a / L=0.3$ in comparison with the full contact case $a /$ $L=1.0$ at a BHF $15 \mathrm{kN}$ and forming speed $150 \mathrm{~mm} / \mathrm{s}$, which verified the improved draw-ability using macro-texture tools.

The improved draw-ability is mainly due to the nonuniform temperature field generated by the macro-tool texture at the flange area. Using such kind of macro-tool texture, simulation work has shown that the temperature of the test piece drops from the initial temperature 470 to $302.2{ }^{\circ} \mathrm{C}$ $(35.7 \%)$ on the left-hand side $(a / L=0.3)$ and $124.6{ }^{\circ} \mathrm{C}$ $(73.5 \%)$ on the right-hand side $(a / L=1.0)$. With the decrease of texture ratio, the lower contact area contributed to a higher test-piece temperature which was reflected by decreasing flange ratio.

Acknowledgments The work described in the paper was supported by the European Commission 7th Framework Programme (Grant agreement no: 604240) as part of the project 'LoCoLite: An industry system enabling the use of a patented materials processing technology for Low Cost forming of Lightweight structures for transportation industries'. Moreover, the contribution of cast and machined blankholder and insert components by Plasmaterm SA are greatly appreciated.
Open Access This article is distributed under the terms of the Creative Commons Attribution 4.0 International License (http:// creativecommons.org/licenses/by/4.0/), which permits unrestricted use, distribution, and reproduction in any medium, provided you give appropriate credit to the original author(s) and the source, provide a link to the Creative Commons license, and indicate if changes were made.

\section{References}

1. Wang L, Strangewood M, Balint D, Lin J, Dean TA (2011) Formability and failure mechanisms of AA2024 under hot forming conditions. Mater Sci Eng A 528(6):2648-2656. doi:10.1016/j. msea.2010.11.084

2. Bhattacharya R, Stanton M, Dargue I, Williams G, Aylmore R (2010) Forming limit studies on different thickness aluminium 6xxx series alloys used in automotive applications. Int J Mater Form 3(1):267-270. doi:10.1007/s12289-010-0758-4

3. Foster AD, Dean TA, Lin J (2013) Process for forming aluminium alloy sheet components, Patent No. EP 2,324,137, January 16

4. Mohamed MS, Foster AD, Lin J, Balint DS, Dean TA (2012) Investigation of deformation and failure features in hot stamping of AA6082: experimentation and modelling. Int J Mach Tool Manuf 53(1):27-38. doi:10.1016/j.ijmachtools.2011.07.005

5. Lloyd DJ (1998) Advances in industrial materials. In: Wilkinson DS, Poole WJ, Alpas A (eds) The metallurgical society of CIM. Montreal, Canada, 3-17

6. Karbasian H, Tekkaya AE (2010) A review on hot stamping. J Mater Process Technol 210(15):2103-2118. doi:10.1016/j. jmatprotec.2010.07.019

7. Merklein M, Lechler J, Stoehr T (2009) Investigations on the thermal behavior of ultra high strength boron manganese steels within hot stamping. Int J Mater Form 2(1):259-262. doi:10.1007/s12289009-0505-x

8. Bosetti P, Bruschi S, Stoehr T, Lechler J, Merklein M (2010) Interlaboratory comparison for heat transfer coefficient identification in hot stamping of high strength steels. Int J Mater Form 3(1): 817-820. doi:10.1007/s12289-010-0895-9

9. Ceretti E, Fiorentino A, Giardini C (2008) Process parameters influence on friction coefficient in sheet forming operations. Int $\mathrm{J}$ Mater Form 1(1):1219-1222. doi:10.1007/s12289-008-0161-6

10. Bariani PF, Bruschi S, Ghiotti A, Michieletto F (2013) Hot stamping of AA5083 aluminium alloy sheets. CIRP Ann Manuf Technol 62(1):251-254. doi:10.1016/j.cirp.2013.03.050

11. Kim H, Sung JH, Sivakumar R, Altan T (2007) Evaluation of stamping lubricants using the deep drawing test. Int J Mach Tool Manuf 47(14):2120-2132. doi:10.1016/j.ijmachtools.2007.04.014

12. Vanhulsel A, Velasco F, Jacobs R, Eersels L, Havermans D, Roberts EW, Sherrington I, Anderson MJ, Gaillard J (2007) DLC solid lubricant coatings on ball bearings for space applications. Tribol Int 40(7):1186-1194. doi:10.1016/j.triboint.2006.12.005

13. Riahi A, Alpas A (2007) Adhesion of AA5182 aluminium sheet to DLC and TiN coatings at $25^{\circ} \mathrm{C}$ abd $420^{\circ} \mathrm{C}$. Surf Coat Technol 202: 1055-1061. doi:10.1016/j.surfcoat.2007.07.085

14. Ni W, Cheng Y, Weiner A, Perry T (2006) Tribological behavior of diamond-like-carbon (DLC) coatings against aluminum alloys at elecated temperatures. Surf Coat Technol 201(6):3229-3234. doi: 10.1016/j.surfcoat.2006.06.045

15. Menezes PL, Kishore, Kailas SV (2009) Influence of surface texture and roughness parameters on friction and transfer layer formation during sliding of aluminium pin on steel plate. Wear 267(910):1534-1549. doi:10.1016/j.wear.2009.06.003

16. $\mathrm{Hu} \mathrm{T,} \mathrm{Hu} \mathrm{L,} \mathrm{Ding} \mathrm{Q} \mathrm{(2012)} \mathrm{Effective} \mathrm{solution} \mathrm{for} \mathrm{the} \mathrm{tribological}$ problems of Ti-6Al-4 V: combination of laser surface texturing and 
solid lubricant film. Surf Coat Technol 206(24):5060-5066. doi:10. 1016/j.surfcoat.2012.06.014

17. Wank A, Reisel G, Wielage B (2006) Behavior of DLC coatings in lubricant free cold massive forming of aluminum. Surf Coat Technol 201(3-4):822-827. doi:10.1016/j.surfcoat.2005.12.043

18. Heinrichs J, Olsson M, Jacobson S (2012) Mechanisms of material transfer studied in situ in the SEM: explanations to the success of DLC coated tools in aluminium forming. Wear 292-293:49-60. doi:10.1016/j.wear.2012.05.033

19. Heinrichs J, Jacobson S (2010) Laboratory test simulation of aluminium cold forming-influence from PVD tool coatings on the tendency to galling. Surf Coat Technol 204(21-22):3606-3613. doi:10.1016/j.surfcoat.2010.04.025

20. Segu DZ, Choi SG, Choi JH, Kim SS (2013) The effect of multiscale laser textured surface on lubrication regime. Appl Surf Sci 270:58-63. doi:10.1016/j.apsusc.2012.12.068

21. Costa HL, Hutchings IM (2009) Effects of die surface patterning on lubrication in strip drawing. J Mater Process Technol 209(3):11751180. doi:10.1016/j.jmatprotec.2008.03.026

22. Costa HL, Hutchings IM (2007) Hydrodynamic lubrication of textured steel surfaces under reciprocating sliding conditions. Tribol Int 40(8):1227-1238. doi:10.1016/j.triboint.2007.01.014

23. Qiu M, Minson BR, Raeymaekers B (2013) The effect of texture shape on the friction coefficient and stiffness of gas-lubricated parallel slider bearings. Tribol Int 67:278-288. doi:10.1016/j.triboint. 2013.08.004

24. Kovalchenko A, Ajayi O, Erdemir A, Fenske G (2011) Friction and wear behavior of laser textured surface under lubricated initial point contact. Wear 271(9-10):1719-1725. doi:10.1016/j.wear.2010.12. 049

25. Rasp W, Wichern CM (2002) Effects of surface-topography directly and lubrication condition on frictional behaviour during plastic deformation. J Mater Process Technol 125-126:379-386. doi:10. 1016/S0924-0136(02)00346-1

26. Lakshmipathy R, Sagar R (1992) Effect of die surface topography on die-work interfacial friction in open die forging. Int J Mach Tool Manuf 2(5):685-693. doi:10.1016/0890-6955(92)90023-A

27. Xie JL, Tan YB, Duan F, Ranjith K, Wong TN, Toh KC, Choo KF, Chan PK (2013) Study of heat transfer enhancement for structured surfaces in spray cooling. App Therm Eng 59(1-2):464 472. doi: 10.1016/j.applthermaleng.2013.05.047

28. Bodin H (2010) Method of hot stamping and hardening a metal sheet, Patent No. US 7,678,208, March 16

29. Franzen V, Witulski J, Brosius A, Trompeter M, Tekkaya AE (2010) Textured surfaces for deep drawing tools by rolling. Int J
Mach Tool Manuf 50(11):969-976. doi:10.1016/j.ijmachtools. 2010.08 .001

30. Kleiner M, Weinert K, Krux R, Kalveram M (2003) Oberflächenstrukturen für Blechumformwerkzeuge-Einfluss spanend hergestellter Werkzeug-Oberflächenstrukturen auf die tribologischen Verhältnisse. WT Werkstattstechnik online 93: 665-670

31. Smith Metals (2015) Aluminium data sheets. http://www. smithmetal.com/downloads/aluminium_datasheets.htm. Accessed 28 Sept 2015

32. Garrett RP, Lin J, Dean TA (2005) An investigation of the effects of solution heat treatment on mechanical properties for AA $6 \times x x$ alloys: experimentation and modelling. Int J Plast 21(8):1640-1657. doi:10.1016/j.jplas.2004.11.002

33. Aginagalde A, Gomez X, Galdos L, Garcia C (2009) Heat treatment selection and forming strategies for 6082 aluminum alloy. J Eng Mater Technol 131(4):044501. doi:10.1115/1.3120384

34. Roliński E, Konieczny A, Sharp G (2009) Nature of surface changes in stamping tools of gray and ductile cast iron during gas and plasma nitrocarburizing. J Mater Eng Perform 18(8):1052-1059. doi:10.1007/s11665-009-9352-7

35. Shang BC, Yin ZM, Wang G, Liu B, Huang ZQ (2011) Investigation of quench sensitivity and transformation kinetics during isothermal treatment in 6082 aluminum alloy. Mater Des 32(7): 3818-3822. doi:10.1016/j.matdes.2011.03.016

36. El Fakir O, Wang L, Balint D, Dear JP, Lin J, Dean TA (2014) Numerical study of the solution heat treatment, forming, and indie quenching (HFQ) process on AA5754. Int J Mach Tool Manuf 87:39-48. doi:10.1016/j.ijmachtools.2014.07.008

37. Lin J, Liu Y (2003) A set of unified constitutive equations for modelling microstructure evolution in hot deformation. J Mater Process Technol 143-144:281-285. doi:10.1016/S0924-0136(03) 00472-2

38. Foster AD, Mohamed MS, Lin J, Dean TA (2008) An investigation of lubricant and heat transfer for a sheet aluminium heat, formquench (HFQ) process. Steel Res Int 79(11):113-120

39. ESI Group (2015) PAM-STAMP sheet metal forming software material data base

40. Bai Q, Lin J, Zhan L, Dean TA, Balint DS, Zhang Z (2012) An efficient closed-form method for determining interfacial heat transfer coefficient in metal forming. Int J Mach Tool Manuf 56:102110. doi:10.1016/j.ijmachtools.2011.12.005

41. Ji K, Fakir OE, Gao HX, Wang LL (2015) Determination of heat transfer coefficient for hot stamping process. Mater Today Proc 2: 434-439. doi:10.1016/j.matpr.2015.05.059 